\title{
Participation in Living Lab: Designing Systems with Users
}

\author{
Birgitta Bergvall-Kåreborn ${ }^{1}$, Debra Howcroft ${ }^{2}$, Anna Ståhlbröst ${ }^{1}$ \\ and Anita Melander Wikman ${ }^{3}$ \\ ${ }^{1}$ Social Informatics, \\ Luleå University of Technology, \\ Luleå, Sweden \\ ${ }^{2}$ Manchester Business School, \\ The University of Manchester, \\ Manchester, United Kingdom \\ ${ }^{3}$ Health and Rehabilitation \\ Luleå University of Technology \\ Luleå, Sweden
}

\begin{abstract}
Drawing on a case study of a living lab, this paper considers the process of participation during the design stages of a health care project for the elderly in Sweden. While participation has an established history, more recently it has been described as an "old, tired concept" that is in need of revitalization in order to cater for changing IS practices. In this paper, we reflect on how participation materializes in a context that is quite dissimilar from more traditional development settings and report on the kinds of practices that may be used to assist design with users.
\end{abstract}

Keywords: Living lab, design with users, participatory design, e-health, formIT.

\section{Introduction}

This paper focuses on living labs and the process of participation that took place during the design of a health project for the elderly. Living labs are an emerging phenomena and largely function as public-private partnerships whereby firms, academics, public sector authorities, and citizens work together for the creation, development, and adoption of new services and technologies in multi-contextual reallife environments (Bergvall-Kåreborn and Ståhlbröst 2009). The purpose of a living lab is to create a shared arena in which digital services, processes, and new ways of working can be developed and tested with users who can stimulate and challenge both research and development. Part of the rationale driving these innovations is the desire to open up company boundaries in order to harvest creative ideas from different stakeholder groups. Most living lab projects are practically focused and are largely neglected in the wider academic literature. 
In this paper, we report on the early stages of a living lab project and link it to the broader field of participatory design (PD). A shared understanding within living lab projects is that users should not be viewed merely as passive information providers: "One thing is common for all of us; the human-centric involvement and its potential for development of new ICT-based services and products" (Open Living Labs, http://www.openlivinglabs.eu/concept.html). We intend to revisit participation in the context of a living lab project, which differs substantially from what is often considered a more traditional IS development project - one with clear organizational boundaries, where the users are often full-time employees using systems in an operational capacity, and where the systems developers guide the direction of the project. The case study illustrates how participation is invoked in real-life situations and aims to show that there is much scope for injecting a more radical element of codesign into these projects, based on the principles and foundations of PD.

\section{Participatory Design}

Involving users in the design and development of information systems has long been a core concept with a distinction between North American and European traditions (Lamb and Kling 2003). The Scandinavian countries have been at the forefront of participatory design that is based on the foundational principle of democracy (Iivari and Lyytinen 1998), which practically translates into people participating in the design process as co-designers (Ehn 2008). Therefore, a key concern is the need to understand how collaborative design processes can be steered by people that are affected by that design. Although the Scandinavia approach is by no means the only driver of participatory approaches, nevertheless it has a radical history with a number of early projects committed to promoting industrial democracy and quality of working life. However, over time this approach has lost much of its critical edge (Iivari and Lyytinen 1998) and, in practice, the notion of joint decision-making and worker influence has virtually disappeared (Kyng 1998).

Indeed, there has been limited attention paid to PD over the last decade, which has been described as an "an old, tired concept" (Markus and Mao 2004) that is desperately in need of revitalization to accommodate more contemporary environments. Yet looking beyond the IS discipline, user participation is advocated within areas like innovation and product development, using concepts such as open innovation, lead users, user-driven design, crowd sourcing, and living lab, although many of these approaches take a managerial as opposed to a user perspective. These technological developments attract limited attention from PD researchers, yet the living lab environment could benefit from drawing on PD principles that are well-established within the Information Systems field. In this paper, it is our intention to draw upon the history of PD to provide broader insights for living lab since this approach differs substantially from what is often considered a more traditional, IS development project. Before turning our attention to the empirical part of the paper, we draw on the wellfounded history of PD to outline three types of participatory processes. The terminology originates from the Riva del Sol conference in 1982 (Briefs et al. 1983) and offers a useful frame for distinguishing between participatory processes. 
- Design for users. With this approach, products and services are designed on behalf of users. While users are consulted, they do not actively participate in the design process, nor do they have influence in the decision-making process, and there is a clear split between what is perceived as technical and nontechnical expertise. The developers have the controlling role, initiating, and running the process and shaping "the solution space" (von Hippel 2001). The objective is to increase developers' understanding of the actual use context by gaining access to users' tacit knowledge, skills, and expertise. One of the main motivations is to improve system quality while gaining commitment and buy-in from users and diffusing tensions and conflicts.

The users play a relatively passive role and are designated consumers of technical expertise (Beath and Orlikowski 1994), providing feedback on items such as requirements specifications and working prototypes. The task of the user is to provide feedback on design rather than to significantly influence or change it. While users are always constrained by the bounds of their knowledge and skills in relation to technical expertise, nevertheless their understanding of their situated context is often undervalued. They are seldom viewed as competent practitioners; they are often perceived as naïve at best (Bannon 1991).

- Design with users. According to this approach, products and services are codesigned by developers and users. The approach is based on the assumption that people have the right to influence the systems that they will use and that, to achieve this, they should have influence and a "voice" throughout the process. The sharp distinction between users and developers is less prominent than design for users, but there are still notable differences in their roles. The process is one of continual iteration between the developers and the users with a focus on knowledge sharing. The developers continue to initiate and run the process, operating as change agents, supporting users in their endeavors and ensuring opportunities are provided for them to take decisions in an informed manner. The developers still predominate with regard to technical activities whereas the users provide direction with the provision of a detailed understanding of the use environment and the appropriateness of ICTs to that particular context. According to this perspective, users are not seen as mere informants: "For us, user participation does not mean interviewing a sample of potential users or getting them to rubber stamp a set of system specifications. It is, rather, the active involvement of users in the creative process we call design" (Greenbaum and Kyng 1991, p. 3).

- Design by users. This approach involves the design of products and services by users with developers providing assistance throughout the process. The users initiate and steer the project while the developers both facilitate and comprise the supporting infrastructure, which can be drawn upon to enhance the users' potential in the design space when needed. In this type of context, the users are "evoked" (Kanstrup and Christiansen 2006), as they draw on their situated knowledge to design and develop product or service innovations that can be supported by the developers. While this approach has the potential to create a radical shift in technological development and open up the design space to a broader constituency (for example, open source software; see Levina 2005), 
equally it could be sabotaged by firms looking to exploit open innovation for profit maximization.

We now turn to our case study, which will be used to illuminate some of the issues discussed above.

\section{MyHealth@Age}

\subsection{Background}

The case is based on MyHealth@Age, which is intended to contribute to the health and well being of the aging population in peripheral and remote communities (specifically Sweden, Norway, and Northern Ireland). MyHealth@Age aims to provide its client population with mobile ICT products and services that help facilitate a more active role in healthcare rehabilitation, sustain autonomous living, and become fully active participants in healthcare and medical treatment programs in cooperation with relevant organizations. Drawing on Nolan's (2006) work on "relationship-centered care," three areas were identified for the project: safety, prescribed healthcare, and social networking. The focus on developing ICTs for elderly persons to manage their own health is somewhat unique, since the majority of IT-based health systems are directed at health organizations as users, rather than having a primary focus on the patients or public. Therefore, it was imperative that the development process would allow for the elderly to take an active role, should they wish to do so. For the purpose of this paper, we will focus on the first part of the development process-understanding user needs - and we concentrate on the process and findings in Sweden.

\subsection{FormIT}

The development methodology that has guided the project-FormIT (full details of FormIT can be found in Bergvall-Kåreborn and Ståhlbröst 2009) -is a humancentered approach to developing IT-based artifacts and services. It aims to facilitate the development of innovative services that are based on a holistic understanding of people's needs, paying due consideration to issues of equity, autonomy, and control in relation to actual use situations. FormIT is grounded in the theoretical streams of soft systems thinking (Checkland 1981; Checkland and Scholes 1990), appreciative inquiry (Cooperrider and Avital 2004; Norum 2001), and NeedFinding (Patnaik and Becker 1999). The process consists of three cycles: concept design, prototype design, and final system design. The focus of this paper is the first phase of the first cycle: appreciate opportunities.

\subsection{The Planning Process}

The planning began by writing the research funding application with partners from the three countries together with three elderly people representing potential users. This provided the elderly with an opportunity to have an impact on the scope of the project, rather than be enrolled at a later stage when project objectives had been 


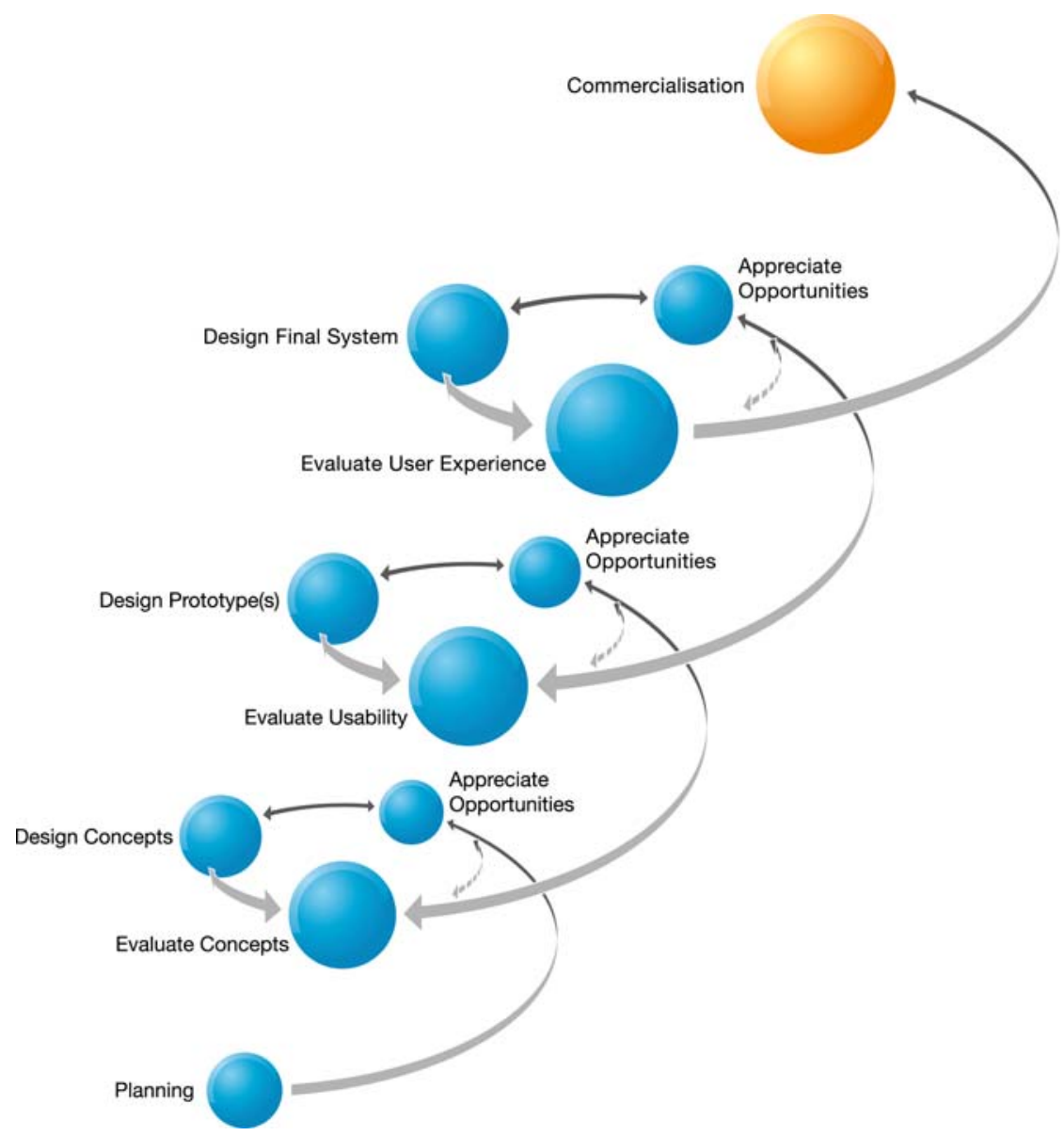

Fig. 1. The FormIT Process

agreed and defined. Effort was made to construct user groups that represent people with different experiences and expertise. The following became involved throughout the process:

- The elderly reference group, who participated in writing the application.

- The elderly organization group, which involved people representing elderly organizations, who are often elderly themselves.

- The elderly representative group, who were recruited to represent the target group of the proposed system.

\subsection{Phase 1: Appreciate Opportunities}

The participants in Sweden consist of the project leader, the reference group (three people), the elderly organizations (five people), the representative group (six to seven 
people), health care professionals, designers and developers from industry, and researchers from the university.

We began by considering how to recruit members of the representative group to denote diverse user needs. Thus we aimed to cover users aged between 55 and 85; a mix of male and female; a mix of single and living with a partner; a varied geographical placement of central, urban and rural; users who are ICT-proficient and familiar with mobile/PCs; users who are in reasonably good health but with some conditions such as high blood pressure, diabetes, osteoporosis, heart problem, or respiratory disease.

Focus group interviews with the representative elderly group: A focus group was held because of the advantages of this approach for assembling data on experiences, beliefs, attitudes, and group interaction (Morgan 1997). It was intended to create a situation whereby the users felt able to discuss their needs and difficulties, since research has shown that it is relatively easy for people to talk about their everyday experiences rather than suggest potential technological solutions. The process was informal as it was intended that the participants in the study would also guide the research. The discussion lasted for 90 minutes and was recorded and transcribed.

The focus group proved to be a positive experience for the facilitators (the researcher and a developer), providing insight into the different perspectives of the users. However, while the participants appeared to enjoy discussing health and other related issues with their peers, nevertheless they found it a challenge to envision what they may need for support, how this could potentially improve the quality of their lives, and the role that could be played by technology.

Cultural probe with the representative elderly group: We wanted to create ways for the elderly to express themselves more naturally in their everyday context, free from the constraints of facilitator guidance. With this in mind, we distributed disposable cameras and notebooks and asked the elderly to photograph situations where they felt secure or insecure; when they were enjoying a social occasion, or felt hindered from participation in a social occasion. We also requested they write a few lines of narrative to accompany each picture, describing how it made them feel. If taking photographs was inappropriate, note-taking would suffice. This was to be carried out for two weeks, the aim being to gain an understanding of the feelings and experiences of potential users in their everyday situations. From the designers' perspective, the data offers real insight into understanding "a day in the life" of elderly people at a fairly intimate level.

Analyzing and tracing user needs: Next, a number of needs were interpreted by the researchers from the statements and stories provided by the elderly. While this activity could have been carried out in conjunction with the elderly, we felt that the task was too time-consuming and that it would be worthwhile for the researchers to interpret their stories and ask for feedback.

Aware of the need to move toward a more thematic approach, we were concerned that our interpretations should be transparent and could be traced back to user statements and so this information was linked together graphically. This allowed the elderly representative group to provide feedback on areas of misunderstanding. A common problem when generating user requirements is that the process is often 
opaque and users are expected to make the mental leap from translating their practical needs into abstract diagrammatical representations.

Ranking the needs: After the needs had been agreed in project meetings by the three elderly groups, we still lacked understanding regarding how representative the needs were and the levels of importance that were attached to each need. We, therefore, developed a questionnaire that was distributed to the representative group. This was designed to avoid leading respondents into particular answers and care was taken to vary the format of questions to allow positive and negative responses. For each need, they were asked to indicate if this applied to their own circumstances and indicate its level of importance using a Likert scale. All of the participants completed the questionnaire and the findings were summarized and discussed at a multi-stakeholder meeting.

The next stage involved clustering needs. Initially, a meeting of multiple stakeholders took place whereby participants formed five smaller groups (of two to four people) to carry out the clustering of needs into categories and then provide a concept/ heading that represented the cluster overall. This resulted in common themes (such as social networks, safety, and medical care), as well as unique categories (such as personal decision-making and self-care) from particular groups. This illustrates the importance of open discussion of both the meaning of the need statements as well as the headings for the clusters.

Additional meetings occurred where the elderly, health professionals, designers, developers, and researchers together discussed how the identified needs may be supported by ICTs. At this phase the project leader, developers, and researcher adopted a more dominant role with the elderly participating in assessment and evaluation, rather than idea generation. Scenarios were developed to depict a "typical user" and their range of needs in order to provide the developers with a broader understanding of the users, their context, and important situations in their life. The aim was to create a bridge between the people carrying out the fieldwork and the system developers, while maintaining close contact with the users. Direct quotations from the users were added in order to give the developers a more diverse picture, adding richness to the scenarios and generating further debate. During this phase, we also identified the needs that fell within the boundary of the project and constituted the base for the conceptual models and requirements. This was done during multi-stakeholder meetings, which are continuing to take place every six weeks to discuss issues concerning needs, design concepts, and emerging requirements from different perspectives.

\section{Summary and Conclusion}

In this paper, it has been our intention to reflect on participatory practices in the context of a living lab, a contemporary phenomenon that is reflective of changing IS environments. MyHealth@Age offers an illustration of how contexts may differ from more traditional development settings and the kinds of practices that may be used for co-design. Working on a project that was focused on wider societal concerns with users that were co-opted on a voluntary basis, meant that the traditional structures of manager- developer-user no longer held and their background and experiences are quite dissimilar from users involved with more traditional in-house development 
projects. It was deemed important to attract a varied group of participants and so effort was put into enrolling the support of users with different experiences. While it can often be challenging to get users to participate in workplace settings, the elderly users appeared keen to be involved and seemed to enjoy the discussions and meetings with the project group.

A recurring challenge within PD concerns how to communicate the needs of users in such a way that developers can understand them while developers need to be able to feed back their understanding of system requirements in a manner such that the users can make sense of it. The project offers an example of how nontechnical participation activities can take place, using primarily paper-based techniques and open debate rather than technical prototypes. It was hoped that this would shift the locus of control to the users, rather than placing them in a position of merely endorsing design decisions that had already been made. The process involved various types of engagement, including focus groups, a questionnaire, diaries, and picturetaking in order to collect different types of data and also to allow for different formats for user contributions, recognizing that some users enjoy open discussion while others who are less vocal may prefer an opportunity to construct a narrative about their experiences or take photographs of significant events. Referring back to the three categories of participation, the project illustrates that it is not the quantity of user involvement that determines the categorization, but rather the influence that is wielded by the users.

Therefore, the quality of interaction among all of the parties has consequences for the project. Building a strong, ongoing relationship with users was crucial, since their involvement required a considerable time commitment on their part as well as psychological involvement. From the outset, the elderly were involved in the research application so that they contributed to scoping the project before the terms of reference had been agreed. From then on, the users took charge of generating needs with the researchers organizing meetings, drawing their attention to different techniques for needs expression, and providing opportunities for them to make decisions and suggestions. In this respect, the design stages can be described as "design with users." This could potentially take on a much more radical element of co-design, should we wish to progress living lab by drawing on the historical roots of PD.

From the perspective of the researchers, this phase has been successful so far, but we acknowledge that it cannot then be assumed that the project from here on will be just as successful, since the link between successful design and successful implementation may be weak, nonexistent, or irrelevant (Markus and Mao 2004). The project is ongoing and future papers will report on how our best intentions to apply the principles of PD to changing IS settings continue to roll out in practice.

\section{Acknowledgments}

This work has been financed by the Swedish Foundation for Strategic Research; Vinnova (Research and Innovation for Sustainable Growth); and the EU through the Northern Peripheral Program. 


\section{References}

Bannon, J.L.: From Human Factors to Human Actors: The Role of Psychology and HumanComputer Interaction Studies in System Design. In: Greenbaum, J., Kyng, M. (eds.) Design at Work: Cooperative Design of Computer Systems, pp. 25-44. Lawrence Erlbaum Associates, London (1991)

Beath, C.M., Orlikowski, W.J.: The Contradictory Structure of Systems Development Methodologies: Deconstructing the IS-User Relationship in Information Engineering. Information Systems Research 5(4), 350-377 (1994)

Bergvall-Kåreborn, B., Ståhlbröst, A.: Living Lab: An Open and Citizen-Centric Approach for Innovation. International Journal of Innovation and Regional Development 1(4), 356-370 (2009)

Briefs, U., Ciborra, C., Schneider, L. (eds.): Systems Design For, With and By the User. NorthHolland, Amsterdam (1983)

Checkland, P.: Systems Thinking, Systems Practice. John Wiley \& Sons, Chichester (1981)

Checkland, P., Scholes, J.: Soft Systems Methodology in Action. John Wiley \& Sons, Chichester (1990)

Cooperrider, D.L., Avital, M. (eds.): Advances in Appreciative Inquiry, Constructive Discourse and Human Organization. Elsevier, Oxford (2004)

Ehn, P.: Participation in Design Things. In: Simonsen, J., Robertson, T., Hakken, D. (eds.) Proceedings of the 10th Anniversary Conference on Participatory Design, Bloomington, Indiana, pp. 92-101 (2008)

Greenbaum, J., Kyng, M.: Introduction: Situated Design. In: Greenbaum, J., Kyng, M. (eds.) Design at Work: Cooperative Design of Computer Systems, pp. 1-24. Lawrence Erlbaum Associates, London (1991)

Iivari, J., Lyytinen, K.: Research on Information Systems Development in Scandinavia: Unity in Plurality. Scandinavian Journal of Information Systems 10(1\&2), 135-185 (1998)

Kanstrup, A.M., Christiansen, E.: Selecting and Evoking Innovators: Combining Democracy and Creativity. Paper presented at Nordic CHI, Changing Roles, Oslo, Norway, October 1418 (2006)

Kyng, M.: Users and Computers: A Contextual Approach to Design of Computer Artifacts. Scandinavian Journal of Information Systems 10(12), 7-44 (1998)

Lamb, R., Kling, R.: Reconceptualizing Users as Social Actors in Information Systems Research. MIS Quarterly 27(2), 197-235 (2003)

Levina, N.: Collaborating on Multiparty Information Systems Development Projects: A Collective Reflection-in-Action View. Information Systems Research 16(2), 109-130 (2005)

Markus, L.M., Mao, J.: Participation in Development and Implementation: Updating an Old, Tired Concept for Todays's IS Contexts. Journal of the Association for Information Systems 5(11-12), 514-544 (2004)

Morgan, D.: Focus Groups as Qualitative Research. Sage Publications, Thousand Oaks (1997)

Nolan, M.: The Senses Framework: Improving Care for Older People Through a RelationshipCentered Approach. Paper presented to Getting Research into Practice (GRIP), University of Sheffield (2006)

Norum, K.E.: Appreciative Design. Systems Research and Behavioral Science (18), 323-333 (2001)

Patnaik, D., Becker, R.: Needfinding: The Why and How of Uncovering People's Needs. Design Management Journal 10(2), 37-43 (1999)

von Hippel, E.: Perspective: User Toolkit for Innovation. The Journal of Product Innovation Management 18(4), 247-257 (2001) 


\section{About the Authors}

Birgitta Bergvall-Kåreborn is a professor in Social Informatics at Luleå University of Technology. Her current research interests concern participatory design in distributed and open environments; human centric and appreciative methodologies for design and learning; as well as he relation between IT-use and IT-design. She can be reached by e-mail at Birgetta.Bergvall-Kareborn@ltu.se.

Debra Howcroft is a professor of Technology and Organizations at Manchester Business School and a member of the ESRC-funded Centre for Research on SocioCultural Change (CRESC). Broadly, her research interests are concerned with the drivers and consequences of socio-economic restructuring in a global context. She can be reached by e-mail at Debra.Howcroft@mbs.ac.uk.

Anna Ståhlbröst is a researcher and project manager at Luleå University of Technology. Her research interest is process-based methods for innovative technology development in living lab environments. These methods specifically focus on generating user needs from different real-world use situations and assessing the users' experience of specific IT artifacts in order to assure that innovative technologies will represent user needs, and thereby give the users an added value. She can be reached by e-mail at Anna.Stahlbrost@ltu.se.

Anita Melander Wikman has an M.Sc, a Fil.Lic. and a Ph.D. in Physiotherapy and is working as a senior lecturer at Luleå University of Technology. Her research interests lies within the field of the empowerment of elderly people and rehabilitation. The focus on her research is to explore how elderly people experience selfdetermination and participation in relation to rehabilitation and how mobile ICT can support them. Anita's intentions is to foreground the client's perspective. She can be reached by e-mail at Anita.Melander-Wikman@ltu.se. 